\title{
Uma Engenharia Didática para o ensino de História da Matemática com o Google Meet durante a pandemia: relato de experiência
}

\section{A Didactic Engineering for teaching the History of Mathematics with Google Meet during the pandemic: experience report}

\author{
${ }^{1}$ Renata Passos Machado Vieira re.passosm@gmail.com \\ ${ }^{2}$ Milena Carolina dos Santos Mangueira \\ ${ }^{3}$ Francisco Regis Vieira Alves \\ ${ }^{4}$ Paula Maria Machado Cruz Catarino
}

\section{RESUMO}

O presente artigo retrata um estudo descritivo e qualitativo, com o objetivo de analisar as concepções dos estudantes do curso de Licenciatura em Matemática, durante as aulas na disciplina de História da Matemática no período de pandemia do novo coronavírus (COVID-19). Assim, foi utilizada a Engenharia Didática, como metodologia de pesquisa, e a Teoria das Situações Didáticas, como metodologia de ensino, abordando assuntos contidos na ementa da disciplina, com o viés de tornar o estudante o protagonista do seu próprio conhecimento. Para isso, as aulas foram ministradas por meio do Google Meet, um recurso computacional o qual foi disponibilizado neste período de pandemia de forma gratuita. Contudo, analisaremos os pontos positivos e negativos dessas aulas, diante desse contexto.

Palavras-chave: Engenharia Didática. COVID-19. Google Meet. Teoria das Situações Didáticas.

\begin{abstract}
The article presents a descriptive and qualitative study, aiming analysing the students conceptions of Mathematics Degree course, over classes of Mathematics History discipline during the new coronavirus (COVID-19) pandemic period. Didactic Engineering was used as research methodology and Didactic Situations Theory as teaching methodology, addressing subjects contained in the discipline's program, in order to making the student the protagonist of his own knowledge. The classes were given through Google Meet, a computational resource which was made available during this pandemic period free of charge. Thus, we analyze the positive and negative points of these classes, given this context
\end{abstract}

Keywords: Didactic Engineering. COVID-19. Google Meet. Didactic Situations Theory.

1 Doutoranda. Universidade Federal do Ceará . http://orcid.org/0000-0002-1966-7097

2 Mestranda em Ensino de Ciências e Matemática. Instituto Federal de Educação, Ciência e Tecnologia do Estado do Ceará. http://orcid.org/00000002-4446-155X

3 Instituto Federal de Educação, Ciência e Tecnologia do Estado do Ceará. http://orcid.org/0000-0002-8059-1159

4 Universidade de Trás-os-Montes e Alto Douro. http://orcid.org/0000-0001-6917-5093 


\section{INTRODUÇÃO}

Um desafio o qual estamos vivenciando neste ano de 2020 é em relação ao processo de ensino, diante desta pandemia em consequência ao novo coronavírus. Assim, os cursos de graduação, pós-graduação, bem como as redes de ensino básica tem-se inovado, realizando diversos procedimentos para que as aulas não sejam paralisadas. Com isso, é dado seguimento ao ensino, por meio do processo de educação a distância, utilizando recursos tecnológicos, como meios cruciais para seguir esse procedimento praticado em sala de aula.

Diante disso, foi então dada a problemática da pesquisa, de como seria dada continuidade às aulas ministradas no curso de Licenciatura em Matemática, na disciplina de História da Matemática, podendo então ser elaborado um relato de experiência para que outros cursos possam assim aplicar determinada pesquisa. Assim, deve-se levar em consideração a motivação dos estudantes e o interesse, para que seja possível facilitar o processo de ensino e aprendizagem desta disciplina.

Com isso, surgiu a pergunta norteadora desta pesquisa: como desenvolver um estudo sistemático referente à sequência de Fibonacci, por meio de uma Engenharia Didática amparada à Teoria das Situações Didáticas, neste período de pandemia num curso de Licenciatura em Matemática?

A partir desta pergunta, foi possível traçar o nosso objetivo geral da pesquisa, como sendo: avaliar o impacto do uso do Google Meet nos seus objetivos de ensino, referente à sequência de Fibonacci, por meio de uma Engenharia Didática amparada à Teoria das Situações Didáticas, durante o período de pandemia, no curso de Licenciatura em Matemática.

Diante disso, será utilizada a metodologia de pesquisa fundamentada na Engenharia Didática (ED) (ARTIGUE, 1988), em associação com a metodologia de ensino, amparada na Teoria das Situações Didáticas (TSD) (BROUSSEAU, 1982), para dar continuidade as aulas da disciplina de História da Matemática do curso de Licenciatura em Matemática de uma instituição de ensino superior no estado do Ceará. Essas duas metodologias visam promover o lado intuitivo dos estudantes, tornando-os capazes de construir o próprio conhecimento. Assim, foram elaboradas situações-problema referente à sequência de Fibonacci, abordando o seu processo histórico e evolutivo, bem como aspectos do campo epistêmico-matemático.

Com isso, seguindo a ementa da disciplina, é então realizado um contrato didático, visando determinar as responsabilidades dos estudantes e do professor. Doravante, as aulas seguirão no formato online, por meio do recurso Google Meet, explorando as fases das metodologias utilizadas, realizando determinadas adaptações durante o processo de aplicação sempre que necessário.

Nas seções subsequentes, será analisada a trajetória metodológica utilizada, discutindo a abordagem ocorrida em cada uma das fases das metodologias utilizadas. Seguindo, tem-se uma breve discussão em relação ao recurso computacional manipulado e, por fim, são elencados os pontos positivos e negativos durante a aplicação desta pesquisa, ressaltando a experiência em realizar tal processo.

\section{2}

\section{TRAJETÓRIA METODOLÓGICA}

A metodologia de pesquisa utilizada foi a ED, que emergiu na Didática da Matemática, com vertente francesa, no início dos anos 80. Essa metodologia permite a investigação das problemáticas referentes a conceitos matemáticos, destacando dificuldades apresentadas durante o processo de aprendizagem (ALMOULOUD, 2007). 
Segundo Almouloud Coutinho (2008) a ED é caracterizada a partir de um esquema experimental, baseado em "realizações didáticas" em sala de aula, onde o professor concebe, realiza, observa e analisa as sessões didáticas construídas pelo próprio. Segundo Artigue et al. (1995) ela é denominada

como uma forma de trabalho comparado com o trabalho de um engenheiro que, para realizar um determinado projeto, se baseia em conhecimentos científicos de sua área e aceita a submeter-se a um controle do tipo científico. Porém, ao mesmo tempo, se encontra obrigado a trabalhar com objetos muito mais complexos que objetos refinados das Ciências e, por tanto, tem que abordar praticamente, com todos os meios disponíveis, problemas que a ciência não deseja ou não pode assumir. (ARTIGUE et al., 1995, p.33-34)

A ED aprecia as produções do professor, consentindo que ele utilize suas produções matemáticas "em pesquisas que estudam os processos de ensino e aprendizagem de um dado objeto matemático e, em particular, a elaboração de gênesis artificiais para um dado conceito” (ALMOULOUD, 2007, p.171). Além disso, essa metodologia está organizada em duas categorias, microengenharia e macroengenharia, onde a primeira refere-se aos fenômenos que decorrem em sala de aula; já a segunda, estuda os fenômenos existentes no processo de ensino e aprendizagem (ARTIGUE et al., 1995). Com isso, essa pesquisa usa a microengenharia, com o intuito de analisar as concepções dos alunos durante as aulas no período de pandemia.

Segundo Pais (2002, p. 101), a ED é um sistema organizado em quatro fases consecutivas: análises preliminares, concepção e análise a priori, experimentação e análise a posteriori e, validação. Na primeira fase, a fase das análises preliminares, inicialmente é realizado um levantamento bibliográfico em torno do objeto matemático, que pretende ser investigado nas situações de ensino. Artigue (1988) afirma que esta fase, deve ser analisada de acordo com três dimensões: a epistemológica, cognitiva e didática. A análise epistemológica é quando realiza-se uma revisão bibliográfica, evidenciando a história do conteúdo matemático. A análise cognitiva é relacionada com as características dos alunos que serão analisados, observando o seu conhecimento em relação à temática. Por fim, na análise didática, é observada a maneira que o conteúdo matemático será passado para os alunos.

Na fase de concepção e análise a priori, Alves et al. (2019) descreve essa etapa como o momento de responder às questões levantadas na fase anterior, levantando as variáveis que irão permitir ao professor/pesquisador recursos para que haja uma elaboração das situações didáticas com base da vivência do aluno, com o intuito de fazê-lo superar os obstáculos encontrados. Almouloud e Silva (2012, p. 26) relatam que essas variáveis podem ser microdidáticas ou macrodidáticas. A primeira variável refere-se à organização local da engenharia. Já a segunda, refere-se à organização global da engenharia. Nesta fase, é possível

prever campos de comportamentos e tentar demonstrar como a análise permite controlar seus significados e assegurar que se tais comportamentos esperados ocorreram, é por consequência do desenvolvimento visado pela aprendizagem (ALMOULOUD \& SILVA, 2012, p. 27).

Com isso, recomenda-se que nesta etapa, os conceitos matemáticos investigados sejam apresentados a partir de situações-problema, que segundo Almouloud (2016) essas situações permitam aos alunos investigar e identificar maneiras de solucionar o problema, partindo de conhecimentos prévios e intuitivos. Essas situações-problema, devem possibilitar ao aluno a sua participação efetivamente no seu processo de ensino e aprendizagem.

Por conseguinte, compreende-se a necessidade de aplicar uma metodologia fundamentada na teoria de ensino, a TSD, desenvolvida pelo francês Guy Brousseau. Essa teoria envolve três elementos: o aluno, o saber e o meio (milieu), com o intuito de estudar a interação entre esses elementos. À vista disso, Teixeira e Passos (2013) diz que: 
O objeto central de estudo nessa teoria não é o sujeito cognitivo, mas a situação didática, na qual são identificadas as interações entre professor, aluno e saber. Algum erro cometido pelo aluno, nessa teoria, quando identificado, constitui-se como valiosa fonte de informação para a elaboração de boas questões ou para novas situações problemas que possam atender, mais claramente, os objetivos desejáveis (TEIXEIRA; PASSOS, 2013, p.158).

Assim, a TSD é dividida em quatro etapas didáticas de ensino, sendo elas: ação, formulação, validação e institucionalização (BROUSSEAU, 1986). Na etapa da ação, o aluno se familiariza com a situação proposta e tem a liberdade de pensar em estratégias de soluções, a partir de intuições ou conhecimentos prévios. Assim, pode-se definir e redefinir sua suposta trajetória, para resolução do problema proposto (ALMOULOUD, 2007).

Na etapa de formulação, o aluno apresenta uma estratégia de solução, podendo ser apresentada de forma escrita ou oral. Almouloud (2007) defende que "o objetivo dessa dialética de formulação é a troca de informações”, por isso é possível que ocorra troca de informações entre os alunos e/ou professor. Nesta etapa, o aluno apresenta um raciocínio de natureza teórica e mais elaborado, permitindo formular hipóteses que possam ser validados ou refutados na próxima etapa.

Na validação, os alunos apresentarão os resultados obtidos e tentarão convencer os interlocutores sobre os argumentos referentes às soluções obtidas, passando a utilizar uma linguagem mais formal. Assim, como diz Teixeira e Passos (2013):

Os alunos tentam convencer os interlocutores da veracidade das afirmações, utilizando uma linguagem matemática apropriada (demonstrações); as situações de devolução, ação, formulação e validação caracterizam a situação didática, em que o professor permite ao aluno trilhar os caminhos da descoberta, sem revelar sua intenção didática, tendo somente o papel de mediador (TEIXEIRA; PASSOS, 2013, p.165-166).

Por fim, na última etapa da TSD, a institucionalização, é o momento em que a intenção da atividade proposta é revelada e ainda validar ou refutar as resoluções apresentadas pelos alunos, verificando e discutindo os procedimentos apresentados. Nesse sentido, Pais (2002) explica que esta fase se trata de um "momento onde se tenta proceder a passagem do conhecimento, do plano individual e particular, à dimensão histórica e cultural do saber científico”. No decorrer do processo de aprendizagem, é importante a interação aluno/professor.

Retomando as fases da ED, tem-se a experimentação que é o momento que são aplicadas as situações-problema e registradas todas as ações dos alunos por meio de: fotografias, gravação de voz, anotações, vídeos etc. É nesse momento que deve ser estabelecido o contrato didático, sendo as expectativas do docente em relação aos discentes, e deles em relação ao docente, incluindo ainda a relação do saber e a maneira de como esse saber é tratado por ambos (BROUSSEAU, 1982). Almouloud (2007) esclarece que, numa perspectiva contratual, o estudante deve assumir o compromisso de participar ativamente das fases de ação, formulação e validação. Em contrapartida, o professor deve institucionalizar o saber, pois "ele deve determinar a forma e o conteúdo do saber para o qual ele quer dar um estatuto oficial, levando em conta os efeitos da transposição didática”.

Vale salientar que a transposição didática foi criada por Chevallard (1998) para analisar o sistema didático, em que diz:

Um conteúdo do conhecimento, tendo sido designado como saber a ensinar, sofre então um conjunto de transformações adaptativas que vão torná-lo apto a tomar lugar entre os objetos de ensino. O trabalho que, de um objeto de saber a ensinar faz um objeto de ensino, é chamado transposição didática (CHEVALLARD, 1998, p.39).

Com isso, após a fase da experimentação, é necessário avaliar as hipóteses levantadas na investigação, realizando a última fase da ED, análise a posteriori e a validação. Com isso, tem-se que a análise a posteriori: 
[...] se caracteriza pelo tratamento dos dados colhidos e a confrontação com a análise a priori, permitindo a interpretação dos resultados e em que condições as questões levantadas foram respondidas. Assim, é possível analisar se ocorrem e quais são as contribuições para a superação do problema, caracterizando a generalização local que permitirá a validação interna do objetivo da pesquisa (POMMER, 2013, p. 26).

A ED permite dois tipos de validação: externa e interna. Na interna, são analisados somente os dados em que foi aplicada a metodologia. Na externa, são levados em consideração as turmas em que utilizou a metodologia, e as que utilizou não a utilizaram, comparando os resultados obtidos com os esperados (ALVES, 2014). Contudo, esta pesquisa utiliza apenas a validação interna, uma vez que foi aplicada em um curto período de tempo, numa turma com poucos estudantes matriculados na disciplina.

Contudo, por tratar-se de uma pesquisa com seres humanos, evidencia-se a aprovação do parecer do comitê de ética, sendo este aprovado. Logo, foi solicitado que os alunos assinassem o termo de consentimento livre e esclarecido.

\section{RECURSO COMPUTACIONAL}

O recurso computacional Google Meet, é uma ferramenta que permite a realização de reuniões por meio de chamadas de vídeo, desenvolvido pelo Google. O seu funcionamento inicial era de forma paga, porém, devido a pandemia do novo coronavírus, este recurso foi disponibilizado de forma gratuita até o final de setembro deste ano, sendo possível realizar reuniões com até cem pessoas (JOHNSTON,2017). O programa encontra-se disponível para sistema operacional Windows, macOS e Linux, pelo site e por aplicativos para smartphones, disponíveis em suas respectivas lojas virtuais.

Este recurso representa um dos dois aplicativos que formam o Google Hangouts, sendo portanto o outro, o aplicativo do Google Chat. Lançado em 2017, essa ferramenta foi projetada para clientes do G Suite. Ressalta-se que o $G$ Suite é o serviço do Google que oferece as versões dos produtos do Google, sendo personalizados de diferentes maneiras. Assim, os demais usuários teriam que ser convidados a participar das reuniões, para conseguir acesso de forma gratuita (WIKIPÉDIA, 2020).

Conhecido por apresentar um dos maiores níveis de segurança e privacidade, este recurso realiza uma criptografia dos dados das reuniões, possuindo níveis avançados de segurança computacional, bloqueando assim o acesso de terceiros. Logo, ao criar uma reunião, é então gerado um código criptografado, sendo necessário que o usuário realize um login, informando o código da reunião a qual irá participar. Contudo, é possível agendar uma reunião, convidando os participantes, para que sejam alertados quanto ao horário.

Assim, esse recurso considerado novo no mundo da tecnologia educacional e, por apresentar uma interface intuitiva, foi então selecionado para ministrar aulas online. Com isso, é possível ainda realizar o compartilhamento da tela, fazendo com que o docente utilize tal recurso como sendo o quadro branco existente na sala de aula.

\section{RESULTADOS E DISCUSSÕES}

A aplicação foi realizada no curso de Licenciatura em Matemática do Instituto Federal do Ceará- IFCE, na disciplina de História da Matemática tendo como objeto de estudo matemático a sequência de Fibonacci, uma vez que, as sequências vem sendo estudadas há um tempo no âmbito matemático e fazem parte da ementa da disciplina. A sequência de Fibonacci foi criada pelo italiano matemático Leonardo Pisano (1180-1250) que no ano 1202 descreveu o crescimento de uma população de coelhos a partir do seguinte questionamento: "Quantos pares de coelhos serão produzidos num ano, começando com um só par, se em cada mês cada par gera um novo 
par que se torna produtivo a partir do segundo mês?” (BOYER, 2006), que ao responder essa pergunta apresenta os números dessa sequência satisfazendo a recorrência $F_{n+1}=F_{n}+F_{n-1}, n \geq 1$ e $n \in \square$, com $F_{0}=0$ e $F_{1}=1$ sendo os seus valores iniciais.

Com isso, a partir da situação-problema dos coelhos, a sequência e a recursividade matemática marcam a gênese do método de Fibonacci. Trabalhos envolvendo estes números podem ser encontrados facilmente na literatura matemática, tais como em Santos (2007) e Oliveira (2018), onde apresentam elementos básicos, tais como: sua forma matricial, fórmula de Binet, identidades clássicas em torno desta sequência e ainda a generalização desses números. Quanto aos números gaussianos de Fibonacci e as suas relações recorrentes uni, bi, tri e $n$-dimensionais são apresentados nos trabalhos de Horadam (1993) e Oliveira, Alves \& Paiva (2017). Assim, com base nesses trabalhos, foi realizada a primeira fase da ED, análise preliminar, construindo o campo epistêmico-matemático do objeto de estudo, realizando um levantamento do referencial teórico de Fibonacci, enfatizando o seu processo histórico e evolutivo de forma online.

Na segunda fase, concepção e análise a priori, foram elaboradas situações de ensino, com base na TSD, destacando as propriedades e teoremas matemáticos evidenciados no referencial teórico, o qual, foi divulgado para os estudantes, além de realizada uma aula expositiva em torno deste processo histórico e evolutivo. Logo, foram analisadas as situações-problema, fundamentadas segundo cada fase da teoria de ensino, discutindo os possíveis comportamentos dos estudantes.

Contudo, foi então realizada a terceira fase da ED, experimentação, sendo então aplicadas as situações-problema elaboradas, ocorrendo de forma online. Durante este momento, é necessário um contato com os estudantes participantes da pesquisa, tão logo, devido à pandemia, foi então utilizado o recurso do Google Meet, para coletar os dados. Após as situações-problema serem apresentadas, os estudantes buscaram uma solução com base nos conhecimentos prévios e, às vezes, levantando questionamentos na plataforma. Nesta fase, foi necessário registrar as ações dos estudantes, por meio de prints da tela do computador, retiradas no momento em que determinados participantes estavam explicando a sua resolução para os demais colegas. Foi ainda solicitado, que os estudantes enviassem as fotos das soluções desenvolvidas, devido a aula não poder ser realizada.

Por fim, foi realizada a última etapa da ED, análise a posteriori e validação, na qual o professor recebeu os dados enviados pelos alunos e confrontou os dados com o que se esperava na análise a priori. Assim, foi analisado se o comportamento dos alunos correspondeu ao que foi esperado e, qual procedimento os participantes solicitaram para encontrar a resposta da situação. Diante disso, constatou-se a validade interna desta pesquisa por meio das fases da ED em conteúdo matemático, permitindo aprimorar o ensino e aprendizagem dos estudantes em relação ao estudo sistemático da sequência de Fibonacci, alcançando assim o objetivo geral desta pesquisa.

Vale destacar que validade interna, segundo Alves (2016) retrata que "uma comparação das produções dos estudantes antes ou ao longo da sequência, ou ainda após experimentação em sala, o que pode ocorrer por meio de entrevistas individuais ou em grupo, bem como por meio de questionários. E, também, por meio da comparação de produções externas, envolvendo outros alunos não submetidos à mesma sequência estruturada de ensino.”

Com base nos relatos de experiências de Aragão et al. (2019) e Mendonça, Majerowicz e Costa (2018), foi possível direcionar esta pesquisa, contribuindo com fundamentos teóricos. Com isso, as aulas deste trabalho tiveram início em abril de 2020, de forma paga pelo Google Meet, porém em maio houve a liberação da ferramenta, tornando-a gratuita para a realização das vídeo chamadas. Assim, no horário das aulas da disciplina, foram agendadas reuniões, como meio de transmitir as aulas de modo virtual, visando dar continuidade à disciplina e a coleta de dados durante a fase da experimentação da ED.

Inicialmente foi realizada uma discussão online, com o viés de compreender o contrato didático, destacando a existência de uma relação implícita entre o professor e os estudantes, sendo portanto, estabelecida de 
acordo com o comportamento dos envolvidos na pesquisa. É importante destacar que esta prática, influencia diretamente no processo de aprendizagem dos estudantes.

Foi firmado um acordo de convivência entre os estudantes participantes, destacando: a importância de manter os microfones desligados, devido aos ruídos externos do ambiente em que estavam presentes, podendo atrapalhar aos demais; foi ensinado as teclas de atalho para ligar e desligar o microfone mais facilmente; e, quando forem discutir as questões e/ou necessitarem falar, escrever uma mensagem no chat, para solicitar a permissão de fala. Além disso, foi então dada a opção de permanecer ou desligar as câmeras, enfatizando que fossem ligadas obrigatoriamente no momento da apresentação dos estudantes. Contudo, foram selecionados ainda dois alunos do curso de Mestrado Acadêmico em Ensino de Ciências e Matemática, na própria instituição de ensino superior, Instituto Federal de Educação, Ciência e Tecnologia do Estado do Ceará (IFCE), para que cuidassem do processo administrativo da sala de reunião, desligando os microfones dos estudantes que não estivessem seguindo o acordo de convivência e, o outro aluno responsável em responder as mensagens postadas no chat no decorrer das aulas.

Posteriormente, seguiu-se com a aula expositiva, referente ao assunto da sequência de Fibonacci, destacando os seus aspectos históricos e matemáticos. Assim, alguns estudantes puderam continuar os estudos na disciplina de História da Matemática. Temos então na Figura 1, exibida em tela cheia, a discussão dos estudantes em relação à uma determinada atividade proposta, fornecendo a fase da ação e formulação acontecendo. Logo, são debatidas as resoluções obtidas e reformulada a linguagem utilizada, para assim dar continuidade às demais fases fundamentadas na TSD, durante a experimentação da ED.

Figura 1 - Explicação do Aluno pelo Google Meet.

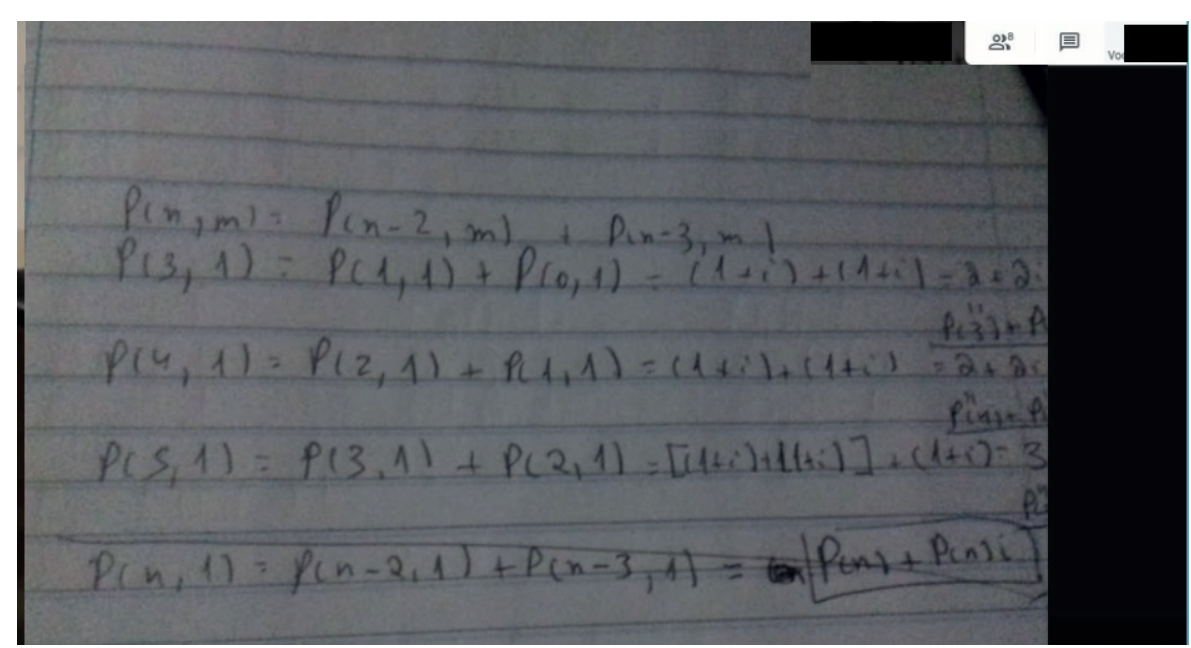

Fonte: Dados da pesquisa. 
Na Figura 2, percebe-se o momento em que um estudante demonstra o seu raciocínio de resolução, diante de uma determinada situação-problema, realizando a fase da validação da TSD.

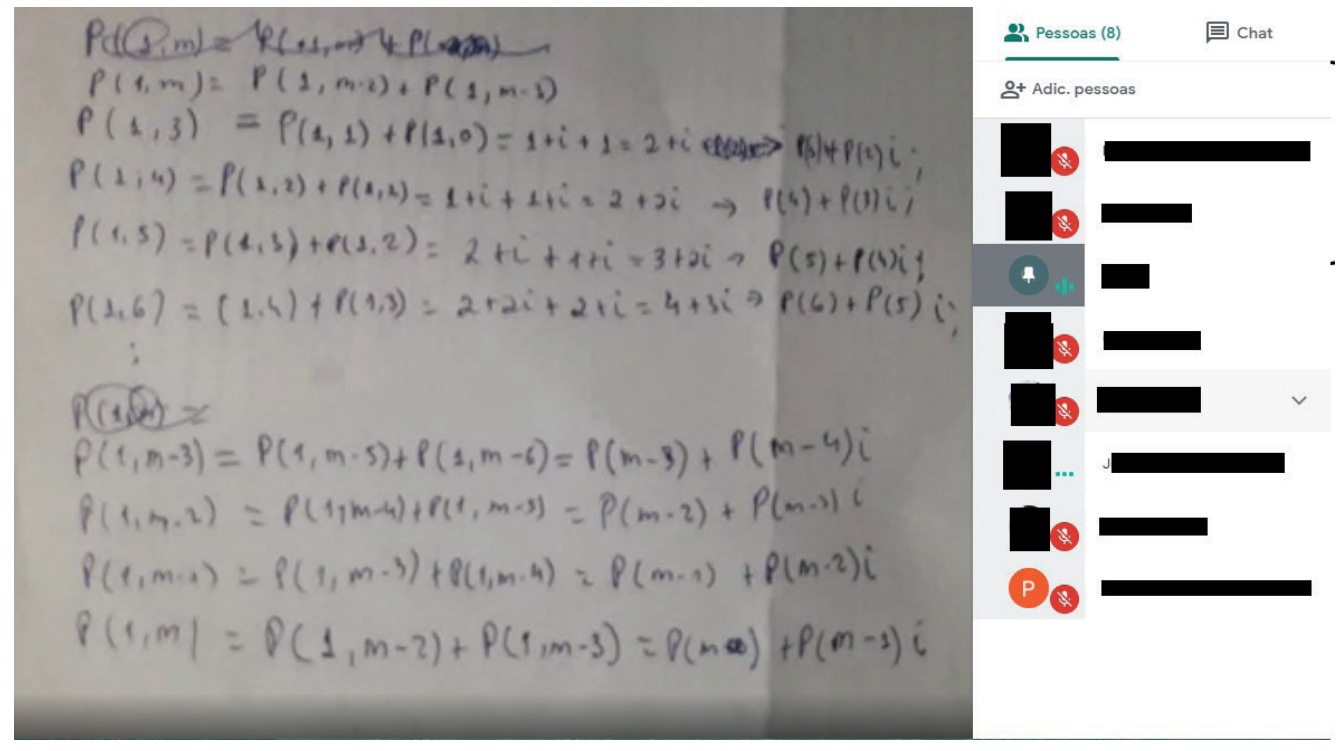

Figura 2 - Aula pelo Google Meet. Fonte: Dados da pesquisa.

A Figura 3 representa o momento em que o professor revela a intenção de uma das atividades propostas (fase da institucionalização da TSD), compartilhando a sua tela e utilizando o programa do computador como sendo uma espécie de quadro branco, realizando assim a abordagem do conteúdo matemático. Com isso, podemos visualizar a interface do recurso tecnológico, percebendo-se a praticidade do seu manuseio.

Figura 3 - Explicação do Professor pelo Google Meet.

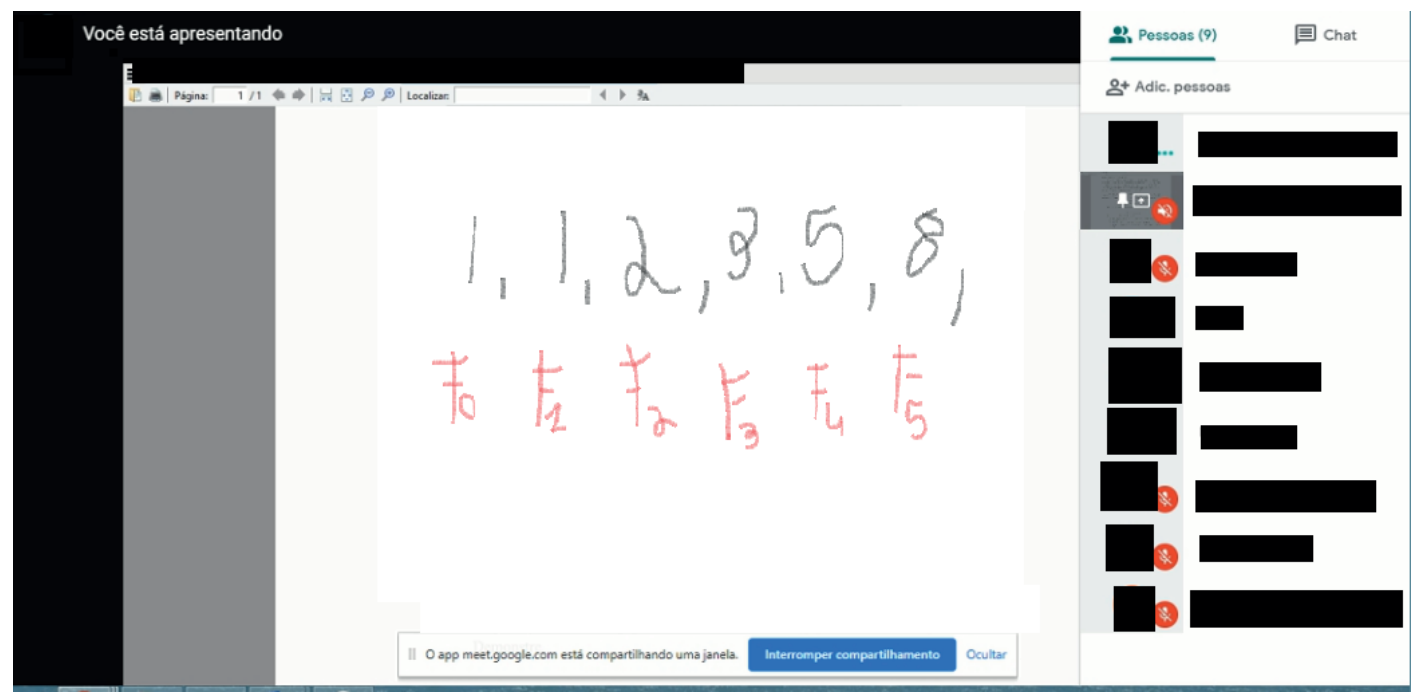

Fonte: Dados da pesquisa.

Após as aulas, foi então realizada uma entrevista com o professor da disciplina, em que pudemos destacar os pontos positivos dessa experiência, como sendo: o fato dos professores, de maneira geral, conhecerem novas ferramentas tecnológicas, que poderão servir mesmo após a pandemia, dando um auxílio para as suas aulas, até mesmo em determinados momentos em que não puderem estar presentes. Outro fato positivo foi em relação às diversas plataformas disponíveis para utilizar o recurso do Google Meet, fazendo com que muitos estudantes 
pudessem participar das aulas através de um smartphone. Logo, com a utilização da ferramenta, foi possível dar continuidade às aulas, não prejudicando o semestre letivo vigente na instituição. Vale destacar que a quantidade de estudantes, durante a pandemia, foi maior, obtendo uma frequência mais elevada neste período.

Alguns pontos negativos foram destacados durante as aulas, sendo eles: o fato de permitir apenas um compartilhamento de tela por usuário na reunião, uma vez que os estudantes solicitaram a alternância de algumas telas durante as aulas, consideradas necessárias por eles; a conexão de rede de alguns estudantes estava oscilando, fazendo com que saíssem e entrassem da sala em determinados momentos e, uma certa demora em analisar as resoluções dos estudantes, perante a ocasião de coleta dos dados ser de forma online, necessitando verificar cada resolução remotamente.

Um determinado estudante, relatou ainda "senti uma pressão menor com esse estudo pelo Meet, já que a presença do professor não está fisicamente próxima. E isso fez com que eu resolvesse os exercícios que não conseguia resolver em sala de aula”. Vale destacar ainda que durante as aulas, apenas um estudante não participou de nenhuma aplicação, relatando que possuía apenas um computador para todos os membros da sua residência, além de o seu celular não possuir espaço disponível para utilizar tal recurso.

Contudo, as fases da ED puderam ser aplicadas e validadas, associando-as com a TSD. Foi possível realizar uma concepção dos estudantes, destacando algumas pequenas dificuldades matemáticas encontradas no decorrer da aplicação, sendo porém contornadas com uma breve explicação sobre o passo indutivo para demonstração dos teoremas. Por fim, os estudantes e o professor da disciplina consideraram a experiência exitosa, sendo possível utilizar as metodologias empregadas de forma a distância.

\section{CONSIDERAÇÕES FINAIS}

Ressalta-se que os estudantes participantes dessa pesquisa, consideraram o presente estudo, como um fator importante no processo de ensino e aprendizagem neste período de pandemia. Assim, puderam dar continuidade às aulas na referida disciplina, utilizando o recurso tecnológico do Google Meet, até então nunca conhecido por eles.

Este relato de experiência, apresentou como tal procedimento pode ser utilizado em sala de aula, podendo realizar adaptações, de acordo com cada situação da instituição e, do meio o qual o estudante está inserido. Contudo, foi possível alcançar o objetivo da pesquisa, desenvolvendo um estudo em relação à ementa da disciplina de História da Matemática, abordando assim o conteúdo da sequência de Fibonacci, realizando um estudo histórico, evolutivo e epistemológico.

As desvantagens encontradas durante a aplicação, foram devido ao fato de que alguns alunos consideraram um pouco mais difícil a interação com os demais colegas durante as discussões das questões. Desse modo, houve a necessidade de o professor realizar uma maior motivação com os participantes, para que ocorresse um bom envolvimento durante a atividade. Além disso, é importante ressaltar as dificuldades de manuseio para com os recursos tecnológicos utilizados, uma vez que alguns desses recursos são considerados novos por muitos.

Por fim, os estudantes puderam construir o conhecimento matemático e histórico dessa sequência, utilizando metodologias francesas, instigando o lado intuitivo e investigativo matemático desse objeto de estudo em análise num contexto ímpar, vivenciado pela pandemia. 


\section{AGRADECIMENTOS}

Os autores agradecem ao professor que se prontificou a elaborar e ministrar a aula e a todos os estudantes envolvidos durante a pesquisa.

A parte de desenvolvimento da pesquisa no Brasil contou com o apoio financeiro do Conselho Nacional de Desenvolvimento Científico e Tecnológico (CNPq) e da Coordenação de Aperfeiçoamento de Pessoal de Nível Superior (CAPES).

A parte de desenvolvimento da pesquisa em Portugal é financiada por Fundos Nacionais através da Fundação para a Ciência e a Tecnologia. I. P (FCT), no âmbito do projeto UID/CED/00194/2020.

\section{REFERÊNCIAS}

ALMOULOUD, S. A. Fundamentos da didática da matemática. Curitiba: UFPR, 2007.

ALMOUlOUD, S. A.; COUTINHO, C. de Q. e S. Engenharia Didática: características e seus usos em trabalhos apresentados no GT-19/ANPEd. Revemat: Revista Eletrônica de Educação Matemática, v. 3, n. 1, p. 62-77, 2008. Disponível em: <https://periodicos.ufsc.br/index.php/revemat/article/view/19811322.2008v3n1p62/12137>. Acesso em: 20 mai. 2020.

ALMOULOUD, S. A. Modelo de ensino/aprendizagem baseado em situações-problema: aspectos teóricos e metodológicos. Revemat: Revista Eletrônica de Educação Matemática, v.11, n. 2, p. 109-141, 2016. doi: https://doi.org/10.5007/1981-1322.2016v11n2p109.

ALVES, F. R. V. Análise preliminar e análise a priori: Situações didáticas envolvendo a noção de integrais múltiplas. Reportes de Investigación, p. 1-9, 2014.

ALVES, F. R. V. Engenharia Didática: implicações para a pesquisa no âmbito do ensino em análise complexaac. Ciência e Natura, v. 38, n. 2, p. 694-715, 2016.

ALVES, F. R. et al. Ensino de ciências e educação matemática 3 [recurso eletrônico] Organizador Felipe Antonio Machado Fagundes Gonçalves. Capítulo 2 - Engenharia Didática para o ensino da sequência de Padovan: um estudo da extensão para o campo dos números inteiros. Ponta Grossa, PR: Atena Editora, 2019. doi:10.22533/at.ed.0901922112. 2019.

ARAGÃO, J. C. S. et al. Produção de vídeos como material didático de apoio para aprendizagem em saúde da mulher: relato de experiência. Revista Práxis, v. 11, n. 22, p. 45-52, 2019. Disponível em: < http://revistas. unifoa.edu.br/index.php/praxis/article/view/2729/2482>. Acesso em: 19 mai. 2020.

ARTIGUE, M. Ingénierie didactique. Recherches en Didactique des Mathématiques, v. 9, n. 3, p. 281-308, 1988. Disponível em: < http://www.cfem.asso.fr/actualites/archives/RDM9.3M.ArtigueIngenierieDidactique. pdf/at_download/file>. Acesso em: 28 ab. 2020.

ARTIGUE, M. et al. Ingenieria didactica en educacion matematica: un esquema para la investigacion y la innovacion en la enseñanza y el aprendizaje de las matematicas. Bogotá: una empresa docente \& Grupo Editorial Iberoamérica, 1995. Disponível em: < https://core.ac.uk/download/pdf/12341268.pdf>. Acesso em: 07 abr. 2020. 
BOYER, C. História da matemática; revista por c. Merzbach, tradução Elza F. Gomide. 2a ed, Sao PauloSP: Ed. Edgard Blucher LTDA, 2006.

BROUSSEAU, G. D'un problème à l'étude à priori d'une situation didactique. Deuxième École d’Été de Didactique des mathématiques, Olivet, p. 39-60, 1982.

BROUSSEAU, G. Fondements et méthodes de la didactique des mathématiques. Recherches en Didactique des Mathématiques, v. 7, n. 2, p. 33-115, 1986. Disponível em:< https://revue-rdm.com/1986/fondements-etmethodes-de-la/>. Acesso em: 12 maio 2020.

CHEVALLARD, Y. La transposición didáctica: del saber sabio al saber enseñado. [S.l.]: Buenos Aires: Aique, 1998.

HORADAM, A. F. Quaternion recurrence relations. Ulam Quarterly, v. 2, p. 23-33, 1993. Disponível em: < http://ulamquarterly.dyndns.org/VIEW2.2/horadam.pdf>. Acesso em: 15 abr. 2020.

JOHNSTON, S. Meet the new Hangouts. Google. Archived from the original on March 14, 2017. Disponível em: < https://techcrunch.com/2020/04/29/google-is-making-meet-free-for-everyone/>. Acesso em: 10 mai. 2020.

MENDONÇA, F. C. R.; MAJEROWICZ, S.; COSTA, M. O filme como estratégia de ensino da Metodologia da Pesquisa: relato de experiência. Revista Práxis, v. 10, n. 20, p. 95-105, 2018. Disponível em: < http://revistas. unifoa.edu.br/index.php/praxis/article/view/1297/2253>. Acesso em: 12 mai. 2020.

OLIVEIRA, R. R. Engenharia Didática sobre o Modelo de Complexificação da Sequência Generalizada de Fibonacci: Relações Recorrentes N-dimensionais e Representações Polinomiais e Matriciais. Dissertação de Mestrado Acadêmico em Ensino de Ciências e Matemática - Instituto Federal de Educação, Ciência e Tecnologia do Estado do Ceará (IFCE), 2018. Disponível em: < http://pgecm.fortaleza.ifce.edu.br/wp-content/ uploads/2018/10/RANNYELLY_DISSERTACAO_PGECM_IFCE_2018.pdf>. Acesso em: 20 mai. 2020.

OLIVEIRA, R. R. de; ALVES, F. R. V.; PAIVA, R. E. B. Identidades bi e tridimensionais para os números de Fibonacci na forma complexa. C.Q.D.-Revista Eletrônica Paulista de Matemática, v. 11, n. 2, p. 91-106, 2017. doi: 10.21167/cqdvol11ic201723169664rrofrvarebp91106.

PAIS, L. C. Didática da Matemática: uma análise da influência francesa. 2. ed. Belo Horizonte: Autêntica, 2002.

POMMER, W. M. A Engenharia Didática em sala de aula: Elementos básicos e uma ilustração envolvendo as Equações Diofantinas Lineares. São Paulo, 2013. Disponível em: < http://stoa.usp.br/wmpommer/ files/3915/20692/Livro\%20Eng\%C2\%AA\%20Did\%C3\%A1tica\%202013.pdf>. Acesso em: 14 mar. 2020.

SANTOS, A. A. dos. Engenharia Didática sobre o Estudo e Ensino da Fórmula de Binet como modelo de generalização e extensão da Sequência de Fibonacci. Dissertação de Mestrado Acadêmico em Ensino de Ciências e Matemática - Instituto Federal de Educação, Ciência e Tecnologia do Estado do Ceará (IFCE), 2017. Disponível em: < http://pgecm.fortaleza.ifce.edu.br/wp-content/uploads/2016/04/Disserta\%C3\%A7\%C3\%A3ofinalizada-com-a-catalogr\%C3\%A1fica-final.pdf>. Acesso em: 10 mai. 2020.

TEIXEIRA, P. J. M.; PASSOS, C. C. M. Um pouco da teoria das situações didáticas (tsd) de Guy Brousseau. Zetetiké, v. 21, n. 39, p. 155-168, 2013. doi: https://doi.org/10.20396/zet.v21i39.8646602.

WIKIPÉDIA. Desenvolvido pela Wikipedia Foundation. Apresenta conteúdo enciclopédico. Disponível em: $<$ https://en.wikipedia.org/wiki/Google_Meet>. Acesso em: 08 mai. 2020. 